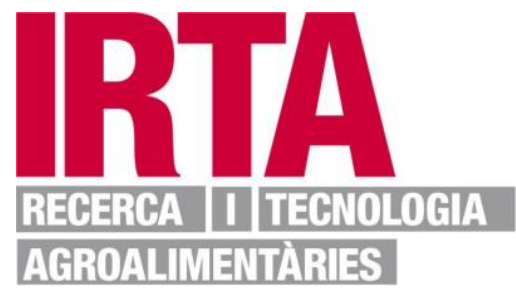

This document is a postprint version of an article published in Science of The Total Environment () Elsevier after peer review. To access the final edited and published work see https://doi.org/10.1016/i.scitotenv.2018.11.318 


\section{Pristine vs. human-altered Ebro Delta habitats display contrasting resilience to RSLR} Patricia Prado, Carles Alcaraz, Xavier Benito, Nuno Caiola, Carles Ibáñez

\section{ABSTRACT}

River deltas are ecologically and economically valuable coastal ecosystems but low elevations make them extremely sensitive to relative sea level rise (RSLR), i.e. the combined effects of sea level rise and subsidence. Most deltas are subjected to extensive human exploitation, which has altered the habitat composition, connectivity and geomorphology of deltaic landscapes. In the Ebro Delta, extensive wetland reclamation for rice cultivation over the last 150 years has resulted in the loss of $65 \%$ of the natural habitats. Here, we compare the dynamics of habitat shifts under two departure conditions (a simulated pristine delta vs. the human-altered delta) using the Sea Level Affecting Marshes Model (SLAMM) under the 4.5 and 8.5 RCP (Representative Concentration Pathways) scenarios for evaluating their resilience to RSLR (i.e. resistance to inundation). Results showed lower inundation rates in the human delta ( $\sim 10$ to $22 \%$ by the end of the century, depending on RCP conditions), mostly due to $\sim 4.5$ times lower initial extension of coastal lagoons compared to the pristine delta. Yet, inundation rates from $\sim 15$ to $30 \%$ of the total surface represent the worst possible human scenario, assuming no flooding protection measures. Besides, accretion rates within rice fields are disregarded since this option is not available in SLAMM for developed dry land. In the human delta, rice fields were largely shifted to other wetland habitats and experienced the highest reductions, mostly because of their larger surface. In contrast, in the pristine delta most of the habitats showed significant decreases by 2100 ( 2 to $32 \%$ of the surface). Coastal infrastructures (dykes or flood protection dunes) and reintroduction of riverine sediments through irrigation channels are proposed to minimize impacts of RSLR. In the worst RCP scenarios, promoting preservation of natural habitats by transforming unproductive rice fields into wetlands could be the most sustainable option.

Key words: SLAMM, rice fields, wetlands, habitat switch, accretion rates, Ebro Delta 


\section{Introduction}

River deltas are among the most productive and highly vulnerable ecosystems in the world (Olson and Dinerstein, 1998; Syvitski et al., 2009). They constitute diverse ecosystems integrated by many different types of wetlands and coastal habitats that provide an array of ecological services such as protection from coastal storms, nutrient cycle regulation, water filtration and fish and wildlife habitat (Wright, 1978). However, river deltas also provide highly productive lands and have been widely used for rice agriculture during centuries (Czetch and Parsons, 2002), thus altering the diversity of natural habitats across vast areas. Today, deltas are seriously threatened by sediment deficit due to dam construction and impoundment, leading to land loss due to coastal erosion and enhanced subsidence during the last 50 to 60 years (e.g., approx. $3.9 \mathrm{~km}^{2}$ of the surface of the Ebro River mouth; Ramírez-Cuesta et al., 2016, and $20 \%$ of the Indus delta plain; Giosan et al., 2014). Besides, their location within or near the range of daily tides expose them to climate change impacts from accelerating rates of Sea Level Rise (SLR) (Ericson et al., 2006), and are likely to be inundated by the end of the century (Syvitski et al., 2009). Because important ecogeomorphic processes such as organic matter accretion, sediment trapping efficiency, and subsidence are associated with vegetation (biomass, productivity and decomposition rates), net land elevation may be influenced by local habitat types (Morris et al., 2002; Nyman et al., 2006). In particular, variability in habitat responses may become especially important when comparing large cultivated areas subjected to biomass extraction and agricultural practices with wetland areas under natural soil dynamics. Although a general habitat conversion to higher salinity tolerance is expected (Day et al., 2000), the distinctive connectivity and ecological functions within altered agricultural systems might lead to a different habitat shift and/ or modify their capacity to compensate for RSLR (degree of inundation). Indirect effects from RSLR such as the extent of the salinity intrusion can also result in important economic losses of agricultural products such as paddy rice production (Genua-Olmedo et al., 2016) and prompt the abandonment of land. Therefore, 
in order to preserve river deltas, it is essential to understand the consequences of RSLR on agricultural exploitation, and how such conditions deviate from pristine systems without human intervention.

Original distribution of wetland habitats has been drastically reduced in world deltas (Coleman et al., 2008). As consequence, ecological modelling has been widely used in predictive studies aimed at reconstructing and forecasting habitat changes for conservation and biological diversity in the face of global change (Guisan and Zimmermann, 2000; Bellard et al., 2012). A number of wetland models incorporating digital elevation models (DEMs) and algorithms simulating local feedbacks of soil processes with broader scale spatial dynamics have been implemented to predict marsh responses to increased rates of RSLR (Rybczyk and Callaway, 2009). In particular, the Sea Level Affecting Marsh Model (SLAMM) was specifically developed to simulate wetland conversion and shoreline modification to assess habitat vulnerability for informing decision-making at local to regional scales. The different environmental processes that affect wetland vegetation are projected under different scenarios of RSLR, allowing marsh migration and producing spatial maps that forecast shifts across different types of marshes and wetland habitats (Clough et al., 2016a). Since its development in the mid-1980s, SLAMM has been successfully applied to multiple studies in Florida, Georgia, Washington, California, and South Carolina (review Mcleod et al., 2010), but is rarely adapted to datasets outside the United States (but see Akumu et al., 2011; Traill et al., 2011). In addition, most of the environments where SLAMM has been applied are tidedominated estuaries (both macrotidal and mesotidal estuaries) in which tidal currents are the dominant force shaping the coastal geomorphology (e.g., Craft et al., 2009; Geselbracht et al., 2011, 2015; Stralberg et al., 2011; Tabak et al., 2016). Hence, SLAMM default assumptions as a response of RSLR, such as the importance of overwash and erosion processes, might not be properly calibrated for Mediterranean estuaries and deltas subjected to microtidal ranges (in general less than $2 \mathrm{~m}$, and particularly in those settings with a tide range less than $0.5 \mathrm{~m}$; 
Ibáñez et al., 2000) although further investigation is needed to test this hypothesis.

Furthermore, concerns regarding the suitability of the model due to the uncertainty involved in selecting many of SLAMM's empirical input parameters such as DEM vertical error, historic trend of sea level rise, and accretion rates have been expressed (Chu-Agor et al., 2011). Yet, the relatively simple implementation of SLAMM, the possibility of specifying accretion rates for some type of wetland habitats, and the detailed, high-resolution habitat maps generated could still provide a useful modelling tool. Here, we test SLAMM to compare the potential effects of RSLR in a region subjected to contrasting habitat distributions as departure conditions to inform management policies and future restoration goals.

The Ebro Delta (Southern Catalonia, NW Mediterranean) constitutes an example of a highly modified human area, with ca. $65 \%$ of the salt marsh-estuarine ecosystems transformed to rice farming over the last 150 years. Rice fields provide an important seasonal habitat for aquatic birds, and fresh water inputs contribute to preventing the saline intrusion among other ecosystem services (e.g. sediment accretion; Calvo-Cubero et al., 2013). However, rice fields may display altered patterns of connectivity due to the presence of irrigation ditches and other man-made structures (Katano et al., 2003) as well as differential rates of vertical accretion (Ibáñez et al., 1997) due to seasonal extraction of ca. 50\% of the plant biomass as rice grain. Besides, plant productivity patterns and the redistribution of sediments from the Ebro River into rice fields through the freshwater canal network might be enhanced at higher elevations close to the river levees rather than the classical bell curve shape between productivity and elevation described for natural tide systems (Morris et al., 2002). Instead, accretion in wavedominated deltas is more likely achieved through pulsing events of wetland flooding following great storms and leading to high sediment inputs (Day et al., 1995). Hence, rice fields might have a distinctive capacity to compensate for present-day rates of secular subsidence in the Ebro Delta (ca. 1-2 mm/yr; Ibáñez et al., 1997) resulting from retention of riverine sediments within upstream dams (Sánchez-Arcilla et al., 2008). It has been estimated that 1 to 4 million 
tons/yr of riverine sediments would be necessary to compensate for the overall deficit within Ebro Delta rice fields and to maintain rice production (Ibáñez et al., 1997).

In this study we employed the Sea Level Affecting Marshes Model (SLAMM) to compare inundation patterns (as an indicator of resilience) and habitat shifts due to RSLR under two contrasting scenarios: with and without human transformation of wetland habitats into farming areas (mostly rice fields). The potential distribution of Ebro Delta habitats under pristine conditions was obtained from the predictive habitat model by Benito et al., (2014).The human delta partially constitutes a irreversible state, since large areas of coastal lagoons were desiccated for rice farming purposes and cannot be returned to their original situation through restoration (see Prado et al., 2017). Both pristine and human-altered habitat maps of the deltaic system, a regionally-specific elevation map (current DEM), SLR projections under a range of future scenarios, and subsidence and accretion rates were used to produce simulations of wetland distributions under future SLR scenarios and to quantify the possible loss of wetland areas in each departing situation (distribution of current habitats under human influence vs. distribution of habitats in the pristine delta). Despite the presence of some soft (sand) dykes bordering the inner part of Ebro Delta bays and coastal lagoons that could help reducing inundation, there are no available maps of these infrastructures that could be included in the simulations. Therefore, for each RCP scenario, our model results represent the worst possible case assuming that no dyke protection or other infrastructures (roads, canals, etc.) are present. This comparative modelling approach (human vs. pristine habitat conditions), although with limitations, could be important for understanding whether or not returning to pristine conditions might help to mitigate for RSLR and for planning habitat restoration actions in the Ebro Delta.

\section{Materials and Methods}

\subsection{Study Area}


132 Basin. The inner limits of the Ebro Delta are defined by several aspects including changes in land composition (disappearance of riverine sediment deposition) and limit of rice cultivation, as well as an elevation increase of up to $5 \mathrm{~m}$. These limits are conventionally used by the local administration and researchers (e.g., Benito et al., 2014; Genua-Olmedo et al., 2016). Although most of the present surface is devoted to rice farming (Fig. 1), the Ebro Delta Natural Park still integrates $\sim 30 \%$ of the remaining wetland surface and features a diverse mosaic of environments including coastal (beaches, coastal plains along two sand-spits, and Salicornia salt marshes), freshwater (Cladium marshes [river and riparian zone not included within the natural park]), and estuarine habitats (coastal lagoons, meadows, reeds and cane communities) hosting a great biodiversity of permanent and migratory birds that attract thousands of visitors per year (Sabater et al., 2010). It is a low-lying area with about $50 \%$ of the total surface below $0.5 \mathrm{~m}$ above mean sea level, and a maximum of about $5 \mathrm{~m}$ close to the river by the town of Amposta (Genua-Olmedo et al., 2016). The vicinity of the Ebro River favors the development of agricultural activities, which are largely devoted to rice production. Also, the production of mussels and oysters in Ebro Delta bays constitutes another major economic activity in the territory (Fig. 1). The delta plain also contains numerous wetland habitats hosting diverse and abundant wildlife, which is protected by the European Union and as the Ebro Delta Natural Park and Biosphere Reserve (Natura 2000 site of UNESCO). Since 1950s, upstream water abstraction and damming for hydroelectric and irrigation purposes caused ca. $40 \%$ decrease in river flow (particularly along the lower stretch) along with dramatic reductions (ca. 99\%) in the amount of sediments available for deposition along the delta plain 153 (e.g. Ibáñez et al., 2012; Rovira et al., 2012). Given the economic importance of the Ebro Delta 154 for rice farming and this great vulnerability of the area to RSLR, engineered structures such as artificial levees were deployed around coastal lagoons and some parts of the shorefront 
adjacent to rice fields, but elevation maps of these infrastructures are not yet available for modelling purposes (see later).

\subsection{Sea Level Affecting Marshes Model (SLAMM)}

Changes in the cover and composition of habitat types in the Ebro Delta in response to accelerated RSLR were modeled using the "Sea Level Affecting Marsh Model" (SLAMM version 6.7). SLAMM employs a decision tree that incorporates geometric and qualitative relationships to simulate the main processes (inundation, erosion by wave action, saturation of the water table, accretion, and salinity) involved in shoreline alterations and conversions of wetland types under the different scenarios of sea-level rise (for more details see Clough et al., 2016b). There are some mandatory and some optional files that need to be uploaded by SLAMM in order to simulate habitat changes at selected RCP scenarios. The first minimum data file that SLAMM needs for functioning is habitat cartography, which included one of two possible habitats departure scenarios: (1) the 2010 CORINE (the Coordination of Information on the Environment program initiated by the EU) habitat distribution maps in the Ebro Delta available from Department of Planning and Sustainability of the Generalitat de Catalunya (http://territori.gencat.cat/ca/01_departament/12_cartografia_i_toponimia/bases_cartografiq ues/medi_ambient_i_sostenibilitat/bases_miramon/territori/29_habitats_1_5000_perfulls/); and (2) a predictive map of the likely "pristine" distribution of wetland habitats (also with the CORINE classification) in the absence of human disturbance in the Ebro Delta built by Benito et al., (2014). Briefly, models of potential natural wetland habitats of the Ebro Delta were developed based on presence/pseudo-absence for each habitat modeled against ecogeographical predictors (surface elevation, distance from the coast, distance from the river and distance from the inner border of the deltaic plain) using Generalized Additive Models (GAMs). Although such pristine scenario might have a larger associated error than that of the human distribution of habitats, it was still considered a good approximation to habitat 
occurrence ( 60 to $98 \%$ accuracy, depending on the habitat; Benito et al., 2014). In both scenarios, minimum and maximum elevation values within each habitat were extracted using ArcGIS and entered into the SLAMM elevation inputs and analyses menu. CORINE habitats were assigned to the habitats of the National Wetlands Inventory (NWI) required by SLAMM (see Table 1). In all cases species composition of the habitats was used to ensure the correct equivalence among categories. Elevation and slope data (also mandatory files) were obtained from the Ebro Delta elevation dataset (DEM) built in 2010 by the Institut Cartogràfic i Geològic de Catalunya (ICGC). (available from Genua-Olmedo et al., 2016). This was, however, not possible because the 6.7 version experienced running problems that need to be solved by SLAMM developers. Hence, default salinity options based on predicted salinities as a function of land-cover type were used (Clough et al., 2016b).

Accretion and subsidence data for the main habitat types were available from unpublished data of the research team (see supplementary material files). The surface elevation tablemarker horizon (SET-MH) method was implemented in 75 points of the Ebro Delta, to determine changes in relative elevation, including sediment accretion, and shallow soil processes (subsidence and expansion due to root production; Cahoon et al., 1995). SETs were installed in 2009 and 2014 and attached to permanent benchmarks in order to achieve high precision measurements of relative wetland surface elevation following the methodology used in a previous setup (Ibáñez et al., 2010). Marker horizons (MH) were deployed using feldspar powder over $100 \times 100-\mathrm{cm}$ plots, with replicate plots at each sampling location. Plots were sampled twice a year (wet and dry season) for SETs and once a year for MH. Accretion values were considered those above the feldspar horizon due to vertical incorporation of sediments and plant biomass, and shallow subsidence was computed as the difference between total elevation change and vertical accretion. On average, this resulted in the following values of 
accretion used in all SLAMM models: Regularly Flooded Marsh Accretion: $2.1 \mathrm{~mm} / \mathrm{yr}$; Irregularly Flooded Marsh Accretion: 2.7 mm/ yr; and Inland Fresh Marsh Accretion: 1.9 mm/ yr. For beach sedimentation rate, we considered a conservative value of $4 \mathrm{~mm} / \mathrm{yr}$ coherent with current rates of SLR necessary to maintain current beach elevation through overwash processes. However, SLAMM does not allow for accretion values for the remaining habitats, including developed dry land, so default conditions have to be assumed. In the case of subsidence, available data points from the ICGC (Pérez -Aragüés and Pipia, 2015) were used to generate subsidence estimates for the whole Ebro Delta using the Kriging geostatistical procedure in ArcGIS 10.3. For the particular case of the Fangar and Banya sand spits where no SETs were deployed, an average of the closets points located on the same type of habitats was used. Both subsidence raster and excel file containing accretion values can be accessed as supplementary material. For each habitat departure scenario (current vs. pristine), the same model was run twice: with and without the generated subsidence raster file in order to evaluate the sensitivity of SLAMM 6.7 to subsidence and to assess the interaction effects with initial habitat types.

The 30-60-90 day inundation levels ( $m$ above the mean tidal level (MTL)) and the 10 year and 100 year storm interval parameters were considered as $\mathrm{H} 1-\mathrm{H} 3=0, \mathrm{H} 4=0.4$, and $\mathrm{H} 5=0.8$ using the DEM file and historical photographs and reports of storm frequencies (Jiménez et al., 2005; Garriga-Sala et al., 2008). The wave erosion model was built with wind-rose angles of the dominant winds taken at 10 min intervals available from the network of oceanographic and meteorological instruments of the Catalonian government (Xarxa d'Instruments Oceanogràfics i Meteorològics (XIOM); Bolaños et al., 2009). The regular and irregular flood-collapse (vertical loss of elevation when regular and irregularly flooded marshes are converted to other habitats; see Clough et al., $2016 \mathrm{~b}$ for details) was considered as ca. $-12.7 \mathrm{~mm}$ from data on similar habitats by Cahoon (2006). Great Diurnal Tide Range (difference between MHHW (mean higher high water) and MLLW (mean lower low water)) was considered as $0.4 \mathrm{~m}$ (Mestres et 
al., 2003); and Historic trend (historic rate of sea level rise) as $2 \mathrm{~mm} /$ year (Church and White, 2011).

Although DEM dataset was available at $1 \mathrm{~m}$ precision SLAMM 6.7, a cell-based model, was run at $10 \mathrm{~m}$ resolution (see also Craft et al., 2009; Stralberg et al., 2011 for resolutions ranging from $\sim 5$ to $30 \mathrm{~m}$ ) due to limitations in the analytical equipment for simulation runs. Model simulations included different IPCC concentration paths of greenhouse gases by the end of the 21st century. The two selected scenarios were the RCP 4.5 (Mean and High) and RCP 8.5 (Mean, High, and Upper) included in the AR5 (Church et al., 2013). The RCP 4.5 is a medium emissions pathway (4.5 $\mathrm{Wm}^{-2}$ radiative forcing) that corresponds to a global warming exceeding $2^{\circ} \mathrm{C}$, whereas the RCP 8.5 is more pessimistic $\left(8.5 \mathrm{Wm}^{-2}\right.$ radiative forcing) and results in a global average warming at the end of the century of about $4^{\circ} \mathrm{C}$ (Church et al., 2013). In addition, we considered the upper limit scenario indicated by Jevrejeva et al., (2014), with a $5 \%$ probability of being exceeded. SLR for each RCP and the upper limit scenario is indicated in Table 2 (Genua-Olmedo et al., 2016). Scenarios were run with a time step of 20 years from 2025 (except for the first time step of 15 years; i.e., 2025, 2040, 2060, 2080, and 2100) in order to allow for observable changes and progressive differences in wetland habitats. In all analyses, SLAMM default elevation distributions for each habitat -calibrated under macrotidal regimes- were corrected with local distribution data extracted by superposing digital maps with the DEM dataset in ArcGIS (see Table 3).

\subsection{Sensitivity Analysis}

Uncertainty analysis provides information about the possible range of habitat changes and the level of certainty in the projected changes (Tabak et al., 2016). Errors that might arise due to the model's inputs parameters include inaccuracies in the experimentally measured values used to feed the model (e.g., constant accretion rates for each habitat, degree of inundation, wind erosion, great diurnal tidal range, etc.), and errors in the projected values of SLR for the 
simulated years and scenarios (see values in Table 2) were investigated through a sensitivity analysis. The SLAMM 6.7 provides a built-in function employing a Monte Carlo method in which model parameter values are randomly selected from user-defined probability distributions as "multipliers" of existing parameter values for a specified number of model iterations (Clough et al., 2016a, b). We ran sensitivity analyses for the human delta under the most extreme possible scenario (RCP 8.5 Upper by 2100). Quantitative variables from the SLAMM site parameters menu (great diurnal tide range, irregular fresh marsh accretion, regular fresh marsh accretion, salt elevation, beach sedimentation rate, regular and irregular flood collapse and inundation levels $\mathrm{H} 1$ to $\mathrm{H} 5$ ) were subjected to deviations of $\pm 10 \%, 20 \%$, $60 \%, 100 \%$ and $250 \%$ of the base input value of each variable. All results and the level of consensus among these iterations were examined in order to determine the magnitude of possible changes and the overall confidence of projected changes.

\section{Results}

\subsection{Subsidence effects}

The inclusion of the subsidence raster showed negligible effect in SLAMM models. In both models departing from the current, human-altered and pristine delta, average annual deviations in percent habitat cover (all habitats excluding the open ocean) between subsidence and no subsidence results ranged between 0.01 and nearly zero (5E-9\%). $0.4 \%)$, inland open water $(0.2 \pm 0.1 \%)$, and irregularly flooded marsh $(0.1 \pm 0.08 \%)$ in the human delta. In the pristine delta variability was lower, ranging from $0.1 \pm 0.05$ to $0.004 \pm$ $0.001 \%$ 
The departing habitat distribution and surface in the human-altered delta and the pristine delta was very different (Fig. 2 to 7). In the human delta, a vast extension of the original coastal lagoons (approx. 15\% of the surface) has been desiccated and clogged with sediments for rice farming purposes over the last 150 years and caused enhanced resilience towards inundation across simulations. In the pristine delta simulations, the presence of these large coastal lagoon areas (approx. $20 \%$ of the Ebro Delta surface) greatly favored the connectivity with the open sea (Alfacs Bay) under the different RCP scenarios of SLR and resulted on increased inundation of the delta surface by the end of the century (RCP 4.5: 9.7 and 10.4\% higher respectively for the Mean and High scenarios; RCP 8.5: 12, 12.3, and 22\% higher, respectively for the Mean, High and Upper scenarios). Yet, model results for the human delta still predict a great loss/ naturalization of agricultural lands (see next section) to RSLR by the end of the century.

\subsection{Habitat effects}

In the initial human delta, the most important habitat was that of developed dry land

(76.8\% of rice fields and other minor agricultural land and villages) with minor contributions of other habitats (0 to $7.2 \%$ ). In contrast, the initial pristine delta mainly included transitional salt marsh (41.7\%), inland open water (ca. 20\%), and inland fresh marsh (ca. 10\%). Under the departing situation of the human delta, open estuarine waters gained $\sim 15$ to $30 \%$ of the delta surface to the other habitats (RCP 4.5 mean to 8.5 Upper), whereas in the case of the pristine delta the increase was considerably higher ranging between $\sim 25$ to $52 \%$ by 2100 .

For the human delta, the most affected habitat was developed dry land which decreased from 31.4 to $62.9 \%$ by the end of the century across RCP scenarios (Fig. 2 to 7). To a lesser extent, other decreasing habitats were inland open water ( $4.5 \%$ in all scenarios), ocean flats 
contrast, the habitats increasing their surface to a greatest extent were estuarine open water (15.1 to $30.2 \%$ ), regularly flooded marsh (13.6 to $15.1 \%$ ), tidal flat (7.9 to $27 \%$ ) and transitional salt marsh (6.4 to 9.1\%). The surface cover of ocean beach increased slightly from RCP 4.5 mean to RCP 8.5 mean ( 0.1 to $0.2 \%)$ but decreased in the more extreme RCP scenarios ( 0.2 to $1.1 \%)$.
In the case of the pristine delta (Fig. 2 to 7 ), the main decreasing habitats from initial conditions by the end of the century were inland open water (18 to 19.7\%) and transitional salt marsh (4 to $32.4 \%$ ), followed by ocean flat ( 4 to $6.5 \%$ ), inland fresh marsh ( 2 to $7.6 \%$ ), riverine tidal ( $2 \%$ in all scenarios) and ocean beach (1 to $6 \%)$. The main increasing habitat was estuarine open water ( 25 to $52.2 \%$ ), followed by tidal flats ( 3 to $17.6 \%$ ) and regularly flooded marsh (5 to $6.2 \%)$.

\subsection{Sensitivity analyses}

Results from sensitivity analyses tested for 2100 under the most extreme scenario (RCP 8.5 Upper) showed different effects depending on the investigated variable, percent deviation from initial conditions, and type of habitat. For great diurnal tidal range resulting changes were small (ca. 0-3\%), except for estuarine beach and ocean flat habitats at deviations of 100 and $250 \%$ from initial values (ca. $7-59 \%$ change; Suppl. Table 1). In contrast, variability in irregularly flooded marsh accretion showed noticeable effects in the cover of inland fresh marsh habitats (IFM) (from ca. 20 to $1933 \%$ variation at 10 to $250 \%$ deviations from initial conditions), but had minor influence in all other habitats. Similarly, variations of 10 to $250 \%$ in the initial values of regularly flooded marsh accretion resulted on estuarine beach variations of 8.7 to $73 \%$ when values were increased and on variations of 0 to $25 \%$ when values were decreased, but had little influence in the remaining habitats (Suppl. Table 1). The salt elevation parameter (the elevation at which dry land and fresh water wetlands begin; SLAMM 6.7 user manual) was the most influential factor across habitats, but was also particularly high for the EB and IFM 
habitats, and for deviations of 40 to $60 \%$ from initial conditions. For sand sedimentation, increasing deviations from initial conditions had a very important effect on EB (30.4 to 217.4\%), ocean beach (OB; 4.4 to $320.8 \%$ ), and OF (18.7 to $8516.7 \%)$. In contrast, both irregular and regular flood collapse SLAMM variables showed almost no effects in any habitats, excepting in EB when deviations from initial conditions increased by 250\% (Suppl. Table 1).

\section{Discussion}

For all RCP scenarios, the resilience (resistance to inundation) of the human delta to RSLR was found to be greater than that of the pristine delta conditions (approx. 10 to $22 \%$ less flooded area by the end of the century). The initial variation in the extension of coastal lagoons (approx. 4.5 times higher under pristine conditions) appears to be the central component determining differences in inundation surface between the two models. In the human delta, areas of large coastal lagoons were desiccated and transformed into rice fields over the last century thereby reducing their connectivity with the bay (Prado et al., 2017). Besides, inundations of 15.1 to $30.2 \%$ of the human delta surface are likely overestimated since they represent the worst possible human scenario, assuming that no protection measures are taken to prevent RSLR and disregarding accretion rates into rice fields. Reductions in the cover of inland fresh marsh towards more salinity tolerant habitats were also observed in both delta scenarios as reported in other regions (see Day et al., 2000). For the human delta, developed dry land (i.e., rice fields) was the main declining habitat (ca. 31 to $63 \%$ by 2100 depending on RCP conditions) and was partly transformed into other wetland habitats. In contrast, in the pristine delta most habitats excepting regularly-flooded marshes and tidal flats would be subjected to sharp decreases by the end of the century (see also Genua-Olmedo et al., 2016).

Overall, our results suggest that unless active human actions are implemented to minimize RSLR ca. 31 to $63 \%$ of agricultural areas will be naturalized or directly lost due to estuarine open water due to RSLR. These adaptation measures could be implemented in the inner part 
of the bays and around coastal lagoons, thus protecting rice fields immediately adjacent to the sea (Nicholls and Minura, 1998). In the frontal part of the Delta, which is subjected to enhanced erosion processes, the best approach would be enhancing the arrival of riverine sediments retained within water reservoirs (Ibáñez et al., 1997; Sánchez-Arcilla et al., 2008). The supply of riverine sediments through irrigation channels could also provide higher elevation throughout the delta (Rovira and Ibáñez, 2007). Although rice farming constitutes the most important socio-economic activity for the region, the creation of new wetland areas could also be an economically viable alternative, granted by the development of an environmentally sustainable touristic industry focused on nature conservation (Figueras et al., 2011). Other local economic activities such as bivalve production might also be altered in more extreme scenarios due to changes in water mass residence time and in the primary production of the bays following the reduction of sand spit areas.

\subsection{Habitat changes from initial conditions}

The initial configuration of habitats appeared to be the most important factor determining differences in the degree of inundation between human and pristine deltas. Results suggest that a larger coastal lagoon adjacent to the Alfacs Bay may raise the flooding risk because it increases the connectivity with or the open sea, whereas both scenarios showed similar effects on sand-spits' loss. In the pristine delta, the presence of a major coastal lagoon system connected to the Alfacs Bay through a thin salt marsh fringe (Benito et al., 2014; Prado et al., 2017) could result in 10 to $12 \%$ higher estuarine open water inundation for the 4.5 mean to 8.5 high RCP scenarios and up to $22 \%$ at the 8.5 Upper scenario by 2100 . This result suggests that lateral marsh edge erosion due to the effect of wind could be a key process favoring the expansion of an initially larger surface area and controlling patterns of sediment deposition (Hopkinson et al., 2018). In the case of the human delta, a plausible hypothesis is also that wetland loss due to reclamation causes concentration of incoming resuspended sediments in 
the remaining natural areas thus providing locally enhanced resilience to SLR. Alternatively, given that most of the habitats occur at elevations that are below sea level, habitat change could be also controlled by the degree of connectivity with the sea and the distribution of habitats accordingly to their salinity tolerance (Rogel et al., 2000). For instance, important areas of inland fresh marsh in the pristine delta were transformed into more salinity tolerant habitats such as transitional salt marsh across RCP scenarios (Day et al., 2000). Also, the role of flood defenses may be a determinant factor controlling habitat distribution and coastal flooding through the effect of coastal squeeze (Rupp-Armstrong and Nicholls, 2007). Hence, the present existence of soft (sand) dykes around coastal lagoon areas and along the inner shoreline of the bays constitutes a limitation in the predictive capacity of the model, which may overestimate patterns of wetland loss by inundation. Some flood protection in both scenarios might have been achieved thanks to the availability of ocean beaches with welldeveloped dunes (Froehle, 2012), but they declined significantly under the most extreme scenarios thus favoring the increase of estuarine open waters.

In the human delta, the most dramatic change aside from inundation was the transformation of ca. 31 to $63 \%$ of rice fields into wetland habitats as expected in lands abandoned to the encroaching sea (FitzGerald et al., 2008). Genua-Olmedo et al. (2016) showed that rice production rates in the Ebro Delta followed an opposite gradient to soil salinity, with reductions between 6.6 and $28.3 \%$ from 2010 to the end of the century depending on each RCP scenario. Hence, the abandonment of rice fields at soil salinities of $\sim 3$ 3.6 psu (Genua-Olmedo et al., 2016) may occur before than habitat changes unless more salinity tolerant genetic varieties are developed to aid crop endurance (Normile, 2008). Although SLAMM assumes that developed dry lands will be always protected against RSLR, our results for the human delta predict that most of these rice fields will be transformed -unless other economic activities such as aquaculture are developed-into transitional salt marsh, regularly flooded marsh, and tidal flat (combined increases from 28 to $51 \%$ of the original Ebro 
Delta surface across RCP scenarios). The unaccounted presence of sand dykes around coastal

417 lagoons could also impede inland migration of intertidal habitats (Rupp-Armstrongt and

418 Nicholls, 2007) and reduce rice field transformations, altering to some extent our obtained results. Yet, saltwater intrusion into rice fields is expected to occur in spite of the presence of dykes and is indicated as the central factor controlling the abandonment of rice fields (GenuaOlmedo et al., 2016). In contrast, the predicted inundation of both sand spits might cause an important impact on the local production of bivalves (mussels and oysters) as a result of alterations in the residence time of water and in the capacity of bays to concentrate phytoplankton (Dame and Prins, 1997).

\subsection{Effects of tidal range and accretion rates}

The SLAMM model has been mostly used to model habitat changes in meso and macrotidal systems across the USA and Canada (e.g., Craft et al., 2009; Stralberg et al., 2011; Geselbracht et al., 2011, 2015; Tabak et al., 2016), but to our knowledge, it has never been applied to microtidal systems such as the Mediterranean Sea. The model assumes that tidal range (meso to macrotidal) determines the range of vertical elevations at which wetlands inhabit, although the 6.7 version allows entering local elevations for each habitat. Yet, when elevation ranges of habitat types overlap considerably (such as in the Ebro Delta), salinity is used to determine habitat switching functions (SLAMM 6.7 Technical Documentation). The accuracy of the salinity algorithm may account for small effects of great diurnal tidal range in sensitivity analyses, except for estuarine beach and ocean flat at deviations rates of 100 and $250 \%$ from initial conditions. Yet, macrotidal marshes (tidal range $>4 \mathrm{~m}$ ) have been indicated to have an order of magnitude greater adaptation to RSLR rates than microtidal marshes (tidal range $<2 \mathrm{~m}$ ) under the same availability of suspended sediment (Kirwan et al., 2010). Under this premise, marshes with low tidal range and low suspended sediment concentrations such as Mediterranean marshes under present conditions could be particularly sensitive to RSLR. According to our 
results, for each RCP scenario approx. 15 to $30 \%$ of the initial human delta surface (including coastal lagoons) and 25 to $52 \%$ of the initial pristine delta was lost to RSLR by the end of the century. These values agree with other static landscape predictions by which 20 to $60 \%$ of the world's coastal wetlands will be inundated by the end of the century due to accelerated RSLR (Nicholls et al., 2007; Craft et al., 2009). Recent more dynamic models, however, predict a lower wetland loss by inundation, ranging from 0 to 30\% (Schuerch et al., 2018). For the Ebro Delta, sensitivity effects due to tidal regimes are difficult to evaluate because natural sediment deposition altered by the construction of many upstream dams that cause erosion in the deltaic plain (Sánchez-Arcilla et al., 2008), and current elevations for initial model conditions are below the sea level in some areas. Although the model showed certain robustness against variations in accretion (with some habitat effects that could be associated to variable inaccuracies in the experimentally measured SET values), pre-dam conditions may have involved even higher depositions than those considered in the sensitivity analysis. Prior to the dams' construction and flow regulations, the amount of sediments arriving into rice fields through irrigation channels from the Ebro River was estimated to be between 3-5 mm/ yr, whereas current rates are possibly close to zero (Ibáñez et al., 1997). For the remaining habitats, our results from the SET-MH method showed similar rates than those reported by Ibáñez et al. (2010) using ${ }^{210} \mathrm{~Pb}$ dating (ca. 2-3 mm/ yr vs. 0.9-1.7 mm/ yr, respectively) so they were not able to compensate an estimated relative RSLR rate for the Ebro Delta of 5 to $8 \mathrm{~mm} /$ yr (Ibáñez et al., 2010). In the deltaic fringe, sediments from eroding stretches are long-shore transported to feed accreting ones but strong erosion rates (exceeding $20 \mathrm{~m} /$ year) in the mouth area are not compensated from upstream sediment supplies and hence constitute an important factor driving vulnerability to RSLR (Sánchez-Arcilla et al., 1998). For instance, the Ebro River mouth, one of the most affected areas by erosive coastal processes, has experienced a shoreline recession of over $2500 \mathrm{~m}$ and about $3.9 \mathrm{~km}^{2}$ over the last century

467 (Palanques and Guillén, 1998; Ramírez-Cuesta et al., 2016). 


\subsection{Limitations of the approach}

470 Several other caveats associated with the tools and approaches we used deserve mention.

471 First, the importance of Ebro Delta wetland loss predicted by SLAMM results under the different RCP scenarios need to be interpreted with caution. According to a meta-analysis conducted by Kirwan et al., (2016) with accretion and elevation data from multiple sites across Canada, the USA, UK, France, and Spain, static landscape models may be overestimating the impacts of RSLR. The main argued reason is that this type of models, including SLAMM, do not account for eco-geomorphic feedbacks allowing accelerated elevation changes to adapt to accelerated RSLR. Hence, the use of constant accretion and elevation rates based on historic trends can even result on dramatic predictions of wetland loss at sites where the marshland is actually expanding (e.g., Kirwan et al., 2016; Schuerch et al., 2018).

Second, in the particular case of the human delta, SLAMM results display the worst possible case scenarios in which rice fields and some other minor agricultural lands are abandoned at the fate of habitat shifts. However, this scenario is unrealistic for socio-economic reasons. Rice agriculture in the Ebro Delta has been a very important economic activity over the last 150 years, boosting different socio-environmental outcomes such as community-supported agriculture and fishery, the Ebro Delta Natural Park, infrastructure investment and population growth (Cardoch et al. 2002). Also, further elevation and extension of sand dykes bordering coastal lagoons and the internal coast of both Ebro Delta bays has been envisaged in order to prevent rice field inundation to RSLR, although the project was stopped due to the economic crises (Genua-Olmedo et al., 2016). Related to this issue, another important shortcoming of SLAMM is that accretion values can only be entered for a selection of wetland habitats, leaving out categories such developed dry land. However, in the particular situation of the Ebro Delta and other similar Mediterranean deltas (Giosan et al., 2014), this is not a realistic scenario because rice fields are exposed to some degree of sediment deposition (possibly $<1 \mathrm{~mm} / \mathrm{yr}$ 
after dams construction). Besides, straw addition is seasonally conducted by local farmers prior to the beginning of each growing season and other management options such as a sediment by-pass from the dammed area to lower stretches of the river could be also possible (Ibáñez et al. 1997, 2010). In a more realistic scenario, SLAMM would also take into account the lack of riverine sediments (Ramírez-Cuesta et al., 2016) and the interplay with other input parameters such as tidal amplitude and local winds, to compute overall losses in surface area. spatially variable subsidence GIS layer, which was also optional for simulations. Although there are no substantial human activities in the Ebro Delta that could enhance subsidence rates (Galloway et al., 1999), the natural compaction of sediments across the different local habitats may account for a vertical height loss of 1-3 mm year (Ibáñez et al., 1997; Sayol and Marcos, 2018), which is not such a minor value. Also importantly, in the absence of a proper functioning for the salinity input raster for the SLAMM version 6.7 our results might be

507 affected to some extent by the default salinity options of the model, which does not allow for a sensitivity analysis on this variable. Despite all of these limitations, results of the different time steps and RCP scenarios are coherent with the results of other local projections for the Ebro Delta (e.g., Genual-Olmedo et al., 2016; Sayol and Marcos, 2018), suggesting the overall reliability of the model.

\section{Conclusions}

514 The presence of large, connected coastal lagoons areas to the sea (semi-enclosed bays) is a 515 major factor determining the degree of inundation under the different RSLR scenarios. For the 516 human delta, subjected to historical desiccation and vertical accretion for rice field exploitation, the model predicts a lower degree of inundation than in the pristine delta, with a progressive transformation of agricultural lands into wetland systems. Similar comparative exercises could be also very useful prior to conducting habitat restoration in other areas 
threatened by SLR, in order to identify natural habitats and spatial distributions that could be more sensitive to inundation. Among major model criticisms, SLAMM lacks the possibility of entering accretion values for developed dry lands, which may nonetheless occur in agricultural systems such as rice fields, and is based on deterministic input variables that tend to overestimate the impacts of RSLR (Kirwan et al., 2016; Schuerch et al., 2018). Although major local towns are located in inner areas relatively protected from RSLR, rice farming, the major local socio-economic activity will be greatly impacted, particularly at salinities of $~ 3-3.6$ psu (Genua-Olmedo et al., 2016). Protection measures such as dykes (already implemented in part) and flood protection dunes (Froehle, 2012), as well as other potential palliative measures such as reintroduction of riverine sediments (Ibáñez et al., 1997; 2010) are recommended, so inundation and, to a lesser extent habitat shifts, will probably have a smaller influence. In more extreme scenarios, unproductive rice fields could be transformed into wetlands for the implementation of alternative activities that could be more economically sustainable given the also important interest of the Ebro Delta as a wildlife refuge in the context of the Mediterranean region (e.g., bird watching). Nonetheless, it is largely unknown how the abandonment of rice fields and the changes in the connectivity between bays and the open ocean might affect the dynamics of this coupled human-environmental system, so the modeling of social, ecologic and economic interactions warrant future studies.

\section{Acknowledgements}

540 This research was supported by the European Union's Seventh Program for Research,

541 Technological Development and Demonstration under grant agreement no.: FP7-ENV-2013-

542 Two-Stage-603396-RISES-AM. Patricia Prado held a postdoctoral contract (DOC-INIA Program)

543 granted by the Spanish National Institute for Agricultural and Food Research and Technology

544 (INIA). Xavier Benito was supported by the National Socio-Environmental Synthesis Center

545 (SESYNC), under funding received from the US NSF DBI-1639145. 


\section{References}

547 Akumu, C.E., Pathirana, S., Baban, S., Bucher, D., 2011. Examining the potential impacts of sea level rise on coastal wetlands in north-eastern NSW, Australia. J. Coast. Conserv. 15(1), $15-22$.

Bellard, C., Bertelsmeier, C., Leadley, P., Thuiller, W., Courchamp, F., 2012. Impacts of climate change on the future of biodiversity. Ecol. Letters. 15(4), 365-377.

Benito, X., Trobajo, R., Ibáñez, C., 2014. Modelling habitat distribution of Mediterranean coastal wetlands: The Ebro Delta as case study. Wetlands 34, 775-785.

Bolaños, R., Jordá, G., Cateura, J., Lopez, J., Puigdefàbregas, J., Gómez, J., Espino, M., 2009. The XIOM: 20 years of a regional coastal observatory in the Spanish Catalan coast. J. Mar. Syst., 77(3), 237-260.

Cahoon, D.R., 2006. A review of major storm impacts on coastal wetland elevations. Estuar. Coasts 29(6A), 889-898.

Cahoon, D.R., Reed, D.J., Day, Jr. J.W., 1995. Estimating shallow subsidence in microtidal salt marshes of the southeastern United States: Kaye and Barghoorn revisited. Mar. Geol. 128(1-2), 1-9.

Calvo-Cubero, J., Ibáñez, C., Rovira, A., Sharpe, P.J., Reyes, E., 2013. Mineral versus organic

Cardoch, L., Day, J.W., Ibáñez, C., 2002. Net primary productivity as an indicator of sustainability in the Ebro and Mississippi deltas. Ecol. Appl. 12, 1044-1055.

Chu-Agor, M.L., Muñoz-Carpena, R., Kiker, G., Emanuelsson, A., Linkov, I., 2011. Exploring vulnerability of coastal habitats to sea level rise through global sensitivity and uncertainty analyses. Environ. Modell. Softw. 26(5), 593-604. 
Craft, C., Clough, J., Ehman, J., Joye, S., Park, R., Pennings, S. et al., 2009. Forecasting the effects of accelerated sea-level rise on tidal marsh ecosystem services. Front. Ecol. Environ. 7(2), 73-78.

Church, J.A., Clark, P.U., Cazanave, A., Gregory, J.M., Jevrejeva, S., Levermann, A.,Merrifield, M.A., Milne, G.A., Nerem, R.S., Nunn, P.D., Payne, A.J., Pfeffer, W.T., Stammer, D., Unnikrishnan, A.S., 2013. Sea level change. In: Stocker, T.F., Qin, D., Plattner, G.-K., Tignor,M., Allen, S.K., Boschung, J., Nauels, A., Xia, Y., Bex, V., Midgley, P.M. (Eds.), Climate Change 2013: The Physical Science Basis. Contribution of Working Group I to the Fifth Assessment Report of the Intergovernmental Panel on Climate Change. University Press, Cambridge, United Kingdom and New York, NY, USA.

Church, J.A., White, N.J., 2011. Sea-level rise from the late 19th to the early 21st century. Surv. Geophys. 32(4-5), 585-602.

Clough, J., Park, R.A., Propato, M., Polaczyk, A., 2016a. SLAMM 6.2 Technical Documentation. Warren: Warren Pinnacle Consulting Inc., Warren, VT, p. 97.

Clough, J.S., Polaczyk, A., Propato, A., 2016b. SLAMM 6.7.beta, Users Manual. Warren Pinnacle Consulting, Inc., Warren, VT, p. 39.

Coleman, J., Huh, O., Braud, D., 2008. Wetland loss in world deltas. J. Coast. Res. 24, 1-14.

Czetch, H.A., Parsons, K.C., 2002. Agricultural wetlands and waterbirds: a review. Waterbirds 25(2), 56-65.

Dame, R.F., Prins, T.C., 1997. Bivalve carrying capacity in coastal ecosystems. Aquatic Ecology, 31(4), 409-421.

Day, J.W., Britsch, L.D., Hawes, S.R., Shaffer, G.P., Reed, D.J., Cahoon, D., 2000. Pattern and process of land loss in the Mississippi Delta: a spatial and temporal analysis of wetland habitat change. Est. Coasts 23(4), 425-438. 
594

595

596

597

598

599

600

601

602

603

604

605

606

607

608

609

610

611

612

613

614

615

616

617

Day, J.W., Pont, D., Hensel, P.F., Ibáñez, C., 1995. Impacts of sea-level rise on deltas in the Gulf of Mexico and the Mediterranean: the importance of pulsing events to sustainability. Estuaries 18(4), 636-647.

Ericson, J.P., Vörösmarty, C.J., Dingman, S.L., Ward, L.G., Meybeck, M., 2006. Effective sea-level rise and deltas: causes of change and human dimension implications. Glob. Planet. Change 50(1), 63-82.

Figueras, M.T.B., Farrés, M.C.P., Pérez, G.R., 2011. The carrying capacity of cycling paths as a management instrument. The case of ebro delta (Spain). Ekológia 30(4), 438-451.

FiztGerald, D.M., Fenster, M.S., Argow, B.A,, Buynevich, I.V., 2008. Coastal impacts due to sealevel rise. Annu. Rev. Earth Planet. Sci. 36, 601-647.

Froehle, P., 2012. To the effectiveness of coastal and flood protection structures under terms of changing climate conditions. Coast. Eng. Proc. 1(33), 60.

Jevrejeva, S., Grinsted, A., Moore, J.C., 2014. Upper limit for sea level projections by 2100. Environ. Res. Lett. 9 (10), 104008. http://dx.doi.org/10.1088/1748-9326/9/10/104008.

Galloway, D.L., Jones, D.R., Ingebritsen, S.E., 1999. Land subsidence in the United States, Vol 1182, US Geological Survey.

Garriga-Sala, J., Loran Benavent, G., Cabrera Tosas, F., 2008. Framework studies for preventing and adapting to climate change in Catalonia. Study N1, Ebro Delta. Departament de Medi Ambient i Habitatge. Oficina Catalana del Canvi Climàtic, p. 206.

Genua-Olmedo, A., Alcaraz, C., Caiola, N., Ibáñez, C., 2016. Sea level rise impacts on rice production: The Ebro Delta as an example. Sci. Tot. Environ.571, 1200-1210.

Geselbracht, L.L., Freeman, K., Birch, A.P., Brenner, J., Gordon, D.R., 2015. Modeled sea level rise impacts on coastal ecosystems at six major estuaries on Florida's gulf coast: Implications for adaptation planning. PloS one 10(7), e0132079. 
Geselbracht, L., Freeman, K., Kelly, E., Gordon, D.R., Putz, F.E., 2011. Retrospective and prospective model simulations of sea level rise impacts on Gulf of Mexico coastal marshes and forests in Waccasassa Bay, Florida. Climat. Change 107(1), 35-57.

Giosan, L., Syvitski, J.P., Constantinescu, S., Day, J., 2014. Climate change: Protect the world's deltas. Nature News 516, 31-33.

Guisan, A., Zimmermann N.E., 2000. Predictive habitat distribution models in ecology. Ecol. Modell. 135, 147-186.

Hopkinson, C.S., Morris, J.T., Fagherazzi, S., Wollheim, W.M., Raymond, P.A., 2018. Lateral marsh edge erosion as a source of sediments for vertical marsh accretion. J. Geophys. Res: Biogeosci. doi.: 10.1029/2017JG004358

Ibáñez, C., Alcaraz, C., Caiola, N., Rovira, A., Trobajo, R., Alonso, M., Duran, C., Jiménez, P.J., Munné, A., Prat, N., 2012. Regime shift from phytoplankton to macrophyte dominance in a large river: top-down versus bottom-up effects. Sci .Total Environ. 416, 314-322.

Ibáñez, C., Sharpe, P.J., Day, J.W., Day, J.N., Prat, N., 2010, Vertical accretion and relative sea level rise in the Ebro Delta wetlands (Catalonia, Spain). Wetlands 30(5), 979-988.

Ibáñez, C., Curcó, A., Day, J.W., Prat, N., 2000. Structure and Productivity of Microtidal Mediterranean Coastal Marshes. In: Weinstein, M., Kreeger, D. (Eds.), Concepts and Controversies in TidalMarsh Ecology. Springer, Netherlands, pp. 107-136.

Ibáñez, C., Canicio, A., Day, J.W., Curcó, A., 1997. Morphologic development, relative sea level rise and sustainable management of water and sediment in the Ebre Delta, Spain. J. Coast Conserv. 3(1), 191-202.

Jiménez, J.A., Sánchez-Arcilla, A., Valdemoro, H.I., 2005. Effects of storm impacts in the Ebro delta coast. Report number: T26-06-02. Integrated Flood Risk Analysis and Management Methodologies (FloodSite), p. 40. 
Katano, O., Hosoya, K., Iguchi, K.I., Yamaguchi, M., Aonuma, Y., Kitano, S., 2003. Species diversity and abundance of freshwater fishes in irrigation ditches around rice fields. Environ. Biol. Fish 66(2), 107-121.

Kirwan, M.L., Temmerman, S., Skeehan, E.E., Guntenspergen, G.R., Fagherazzi, S., 2016. Overestimation of marsh vulnerability to sea level rise. Nat. Clim. Change 6(3), 253260.

Kirwan, M.L., Guntenspergen, G.R., D'Alpaos, A., Morris, J.T., Mudd, S.M., Temmerman, S., 2010. Limits on the adaptability of coastal marshes to rising sea level. Geoph. Res. Let. 37, L23401.

Mcleod, E., Poulter, B., Hinkel, J., Reyes, E., Salm, R., 2010. Sea-level rise impact models and environmental conservation: A review of models and their applications Ocean Coast Managem. 53(9), 507-517.

Mestres, M., Sierra, J. P., Sánchez-Arcilla, A., del Río, J. G., Wolf, T., Rodríguez, A., Ouillon, S., 2003. Modelling of the Ebro River plume. Validation with field observations. Sci. Mar. 67(4), 379-391.

Morris, J.T., Sundareshwar, P.V., Nietch, C.T., Kjerfve, B., Cahoon, D.R., 2002. Responses of coastal wetlands to rising sea level. Ecology 83(10), 2869-2877.

Nicholls, R.J., Wong, P.P., Burkett, V., Codignotto, J., Hay, J., McLean, R., Ragoonaden, S., Woodroffe, C.D., 2007. Coastal systems and low-lying areas, in Climate Change 2007: Impacts, Adaptation and Vulnerability. In: Parry, N.L., Canziani, O.F., Palutikof, J.P., van der Linden, P.J., Hanson, C.E. (Eds.). Contribution of Working Group II to the Fourth Assessment Report of the Intergovernmental Panel on Climate Change, Cambridge Univ. Press, Cambridge, UK, pp. 315-356.

Nicholls, R.J., Minura, N., 1998. Regional issues raised by sea-level rise and their policy implications. Climate Research 11(1), 5-18.

Normile, D., 2008. Reinventing rice to feed the world. Science 321(5887), 330-333. 
Nyman, J.A., Walters, R.J., Delaune, R.D., Patrick, W.H., 2006. Marsh vertical accretion via vegetative growth. Estuar. Coast. Shelf Sci. 69(3), 370-380.

Olson, D.M., Dinerstein, E., 1998. The Global 200: a representation approach to conserving the Earth's most biologically valuable ecoregions. Conserv. Biol. 12(3), 502-515.

Palanques, A., Guillén, J., 1998. Coastal changes in the Ebro delta: natural and human factors. J. Coast Conserv. 4(1): 17-26.

Pérez-Aragüés, F., Pipia, L., 2015. Ebro Delta subsidence. Historical 1992-2010. Ebro Admiclim. Life $13 \mathrm{ENV/ES/001182}$

Prado, P., Alcaraz, C., Jornet, L., Caiola, N., Ibáñez, C., 2017. Effects of enhanced hydrological connectivity on Mediterranean salt marsh fish assemblages with emphasis on the endangered Spanish toothcarp (Aphanius iberus). PeerJ 5:e3009; DOI 10.7717/peerj.3009

Ramírez-Cuesta, J.M., Rodríguez-Santalla, I., Gracia, F.J., Sánchez-García, M.J., Barrio-Parra, F., 2016. Application of change detection techniques in geomorphological evolution of coastal areas. Example: Mouth of the River Ebro (period 1957-2013). Appl. Geogr. 75, $12-27$.

Rogel, J.A., Ariza, F.A., Silla, R.O., 2000. Soil salinity and moisture gradients and plant zonation in Mediterranean salt marshes of Southeast Spain. Wetlands 20(2), 357-372.

Rovira, A., Alcaraz, C., Ibáñez, C., 2012. Spatial and temporal dynamics of suspended load at-acros-section: the lowermost Ebro River (Catalonia, Spain). Water Res. 46, 3671-3681.

Rovira, A., Ibáñez, C., 2007. Sediment management options for the lower Ebro River and its delta. J. Soils Sed. 7(5), 285-295.

Rupp-Armstrong, S., Nicholls, R.J., 2007. Coastal and estuarine retreat: a comparison of the application of managed realignment in England and Germany. J. Coast. Res 23(6), 1418-1430. 
693

694

695

696

697

698

699

700

701

702

703

704

705

706

707

708

709

710

711

712

713

714

715

716

717

Rybczyk, J.M., Callaway, J.C., 2009. Surface elevation models In: Perillo, G.M.E., (ed). Coastal wetlands: an integrated ecosystem approach Amsterdam, Elsevier, Boston, pp. 835853.

Sabater, S., Muñoz, I., Artigas, J., Romaní, A.M., Pérez, M., Duran, C., 2010. Aquatic and riparian biodiversity in the Ebro watershed: prospects and threats. In: The Ebro River Basin, Springer, Berlin Heidelberg, pp. 121-138.

Sánchez-Arcilla, A., Jiménez, J.A., Valdemoro, H.I., Gracia, V., 2008. Implications of climatic change on Spanish Mediterranean low-lying coasts: the Ebro delta case. J. Coast. Res. 24(2), 306-316.

Sánchez-Arcilla, A., Jimenez, J.A., Valdemoro, H.I., 1998. The Ebro Delta: morphodynamics and vulnerability. J. Coast. Res. 14(3), 755-772.

Sayol, J.M., Marcos, M., 2018. Assessing flood risk under sea level rise and extreme sea levels scenarios: application to the Ebro Delta (Spain). J. Geophy. Res. (Oceans) 123(2), 794811. Schuerch, M., Spencer, T., Temmerman, S., Kirwan, M. L., Wolff, C., Lincke, D., McOwen, C.J., Pickering, M.D., Reff, R., Vafeidis, A.T., Hinkel, J., Nicholls, R.J., Brown, S., 2018. Future response of global coastal wetlands to sea-level rise. Nature, 561(7722), 231-247.

Stralberg, D., Brennan, M., Callaway, J.C., Wood, J.K., Schile, L.M., Jongsomjit, D. et al., 2011. Evaluating tidal marsh sustainability in the face of sea-level rise: a hybrid modeling approach applied to San Francisco Bay. PloS one 6(11), e27388.

Syvitski, J., Kettner, A.J., Overeem, I., Hutton, E.W., Hannon, M.T., Brakenridge, G.R., et al., 2009. Sinking deltas due to human activities. Nat. Geosci 2(10), 681-686.

Tabak, N.M., Laba, M., Spector, S., 2016. Simulating the effects of sea level rise on the resilience and migration of tidal wetlands along the Hudson River. PloS one 11(4), e0152437. 
718 Traill, L.W., Perhans, K., Lovelock, C.E., Prohaska, A., McFallan, S., Rhodes, J.R., Wilson, K.A., 2011. Managing for change: wetland transitions under sea-level rise and outcomes for threatened species. Divers. Distrib. 17(6), 1225-1233.

721

Wright, L.D., 1978. River deltas. In: Coastal sedimentary environments, Springer, US, pp. 5-68.

722 


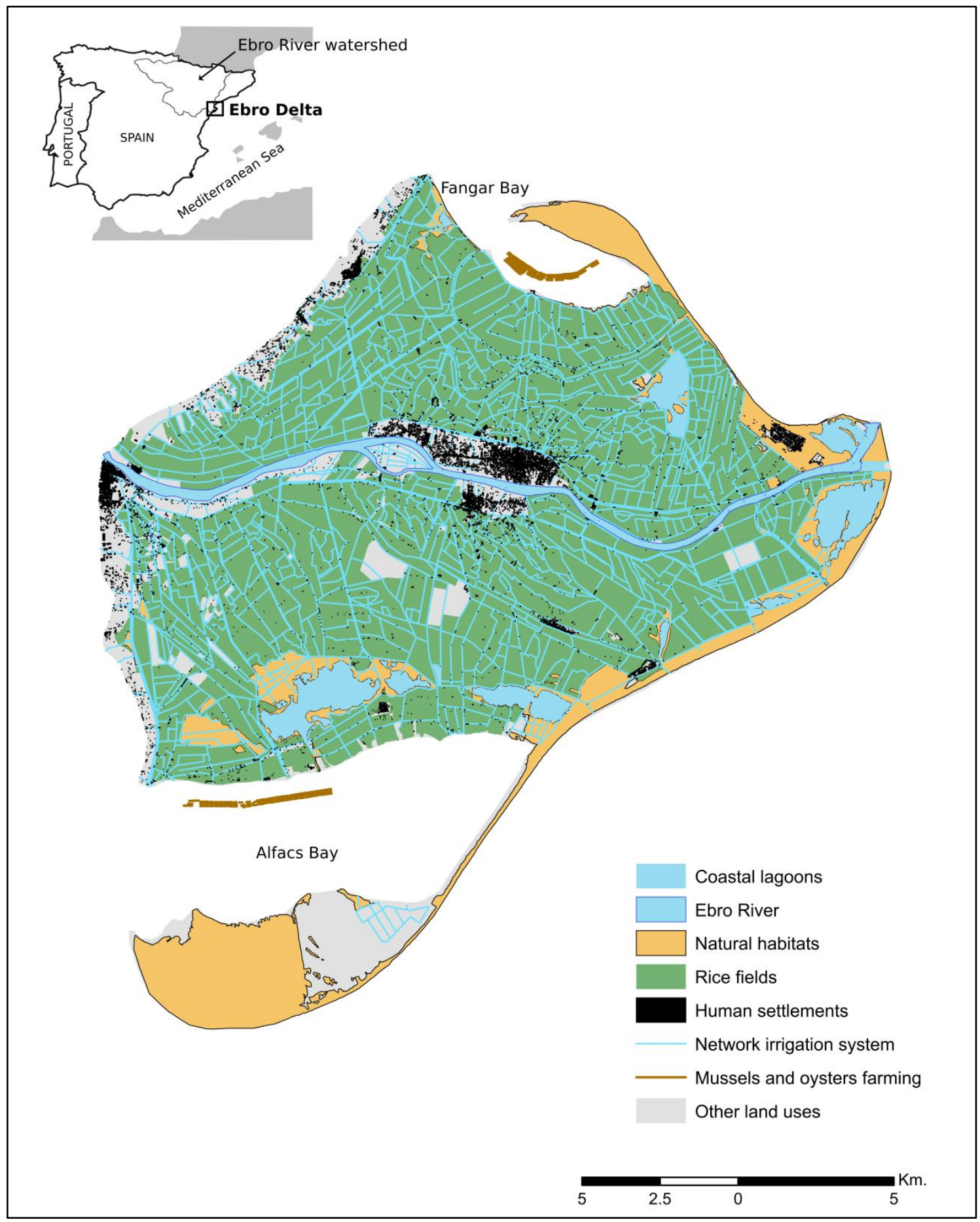

Fig. 1. Map of the Ebro Delta showing the distribution of rice fields and natural habitats

725 (including coastal lagoons, river and wetlands). Human settlements and infrastructures

726 (network irrigation systems and local deployment of mussel and oyster farming structures) are 727 also shown. 

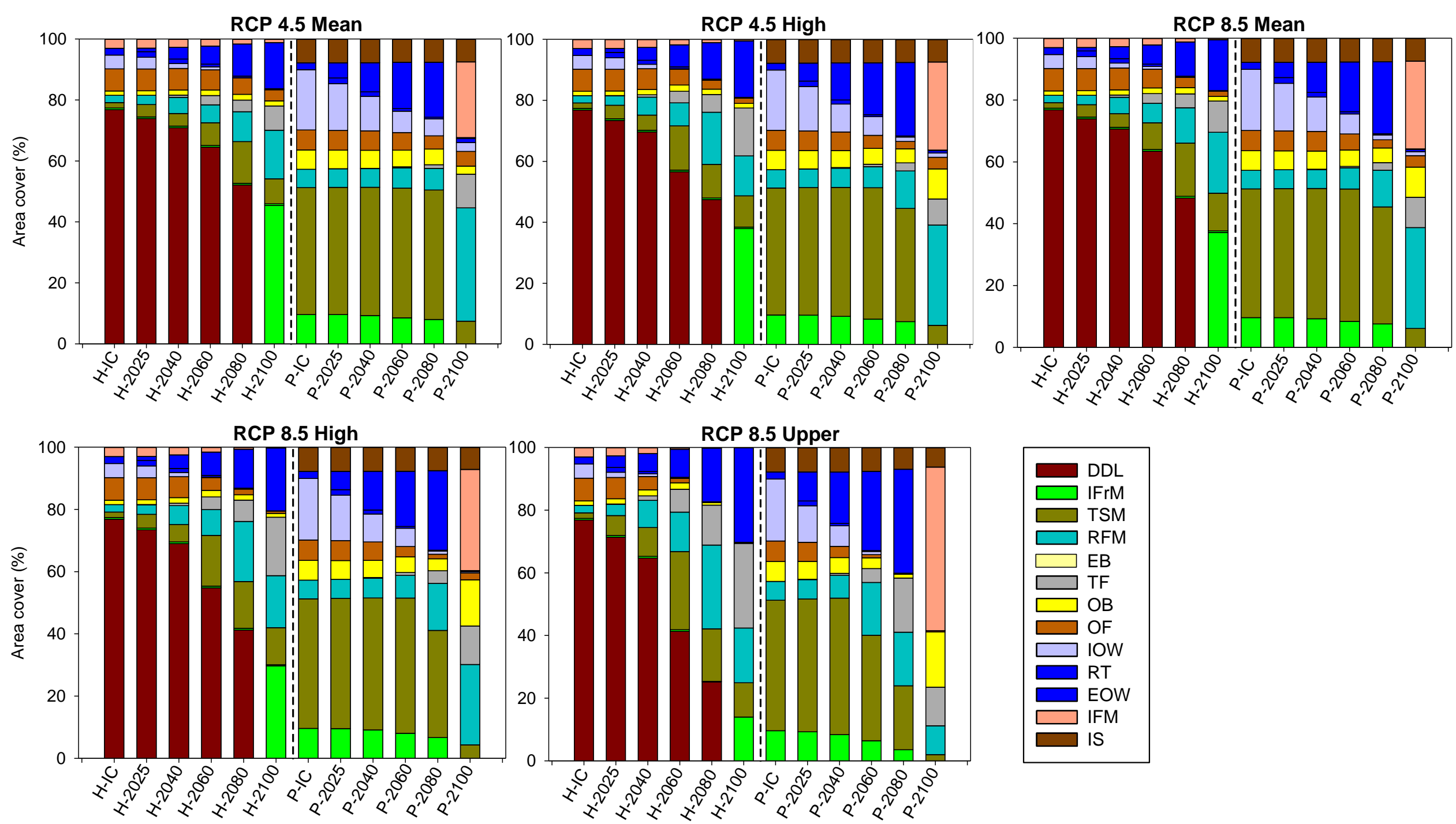

Fig. 2. Percent cover of habitats in the human delta (H) and the pristine delta (P) at each RCP scenario from initial conditions (IC; 2010) to the end of the century. DDL= Developed Dry Land; IFrM= Inland-Fresh Marsh; TSM= Transitional Salt Marsh; RFM= Regularly-Flooded Marsh; EB= Estuarine Beach; TF= Tidal Flat; OB= Ocean Beach; OF= Ocean Flat; IOW=Inland Open Water; RT= Riverine Tidal; EOW= Estuarine Open Water; IFM= Irregularly Flooded Marsh; IS= Inland shore. 


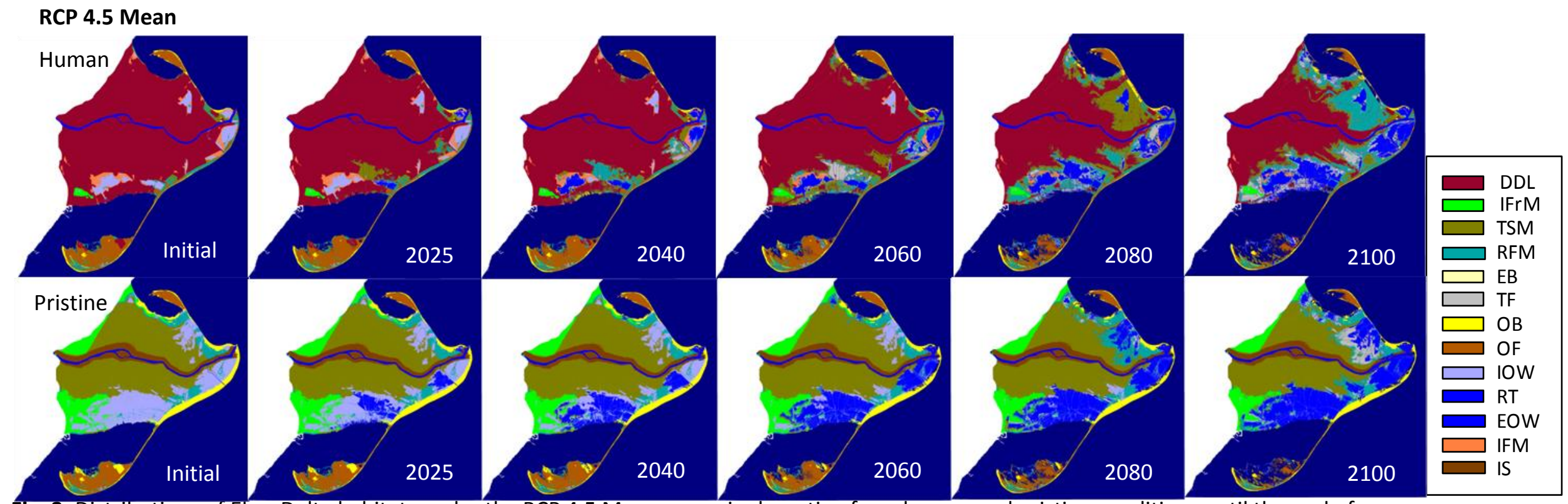

Fig. 3. Distributions of Ebro Delta habitats under the RCP 4.5 Mean scenario departing from human and pristine conditions until the end of the century. Habitat abbreviations as in Fig. 1. 


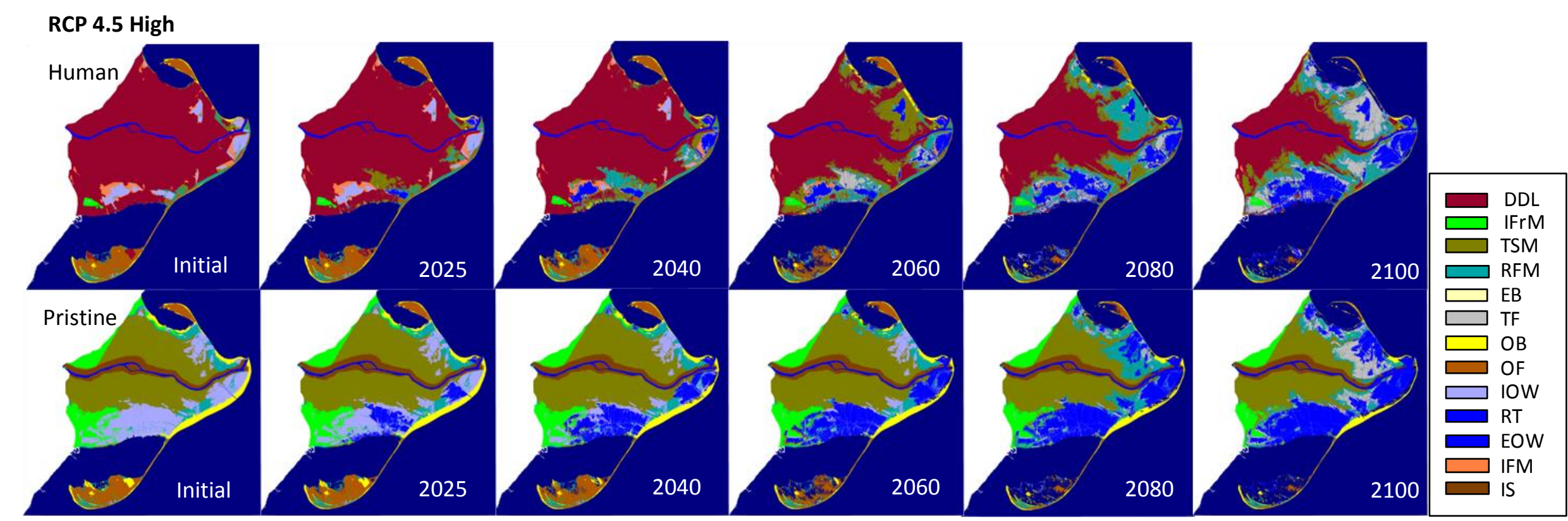

Fig. 4. Distributions of Ebro Delta habitats under the RCP 4.5 High scenario departing from human and pristine conditions until the end of the century. Habitat abbreviations as in Fig. 1. 


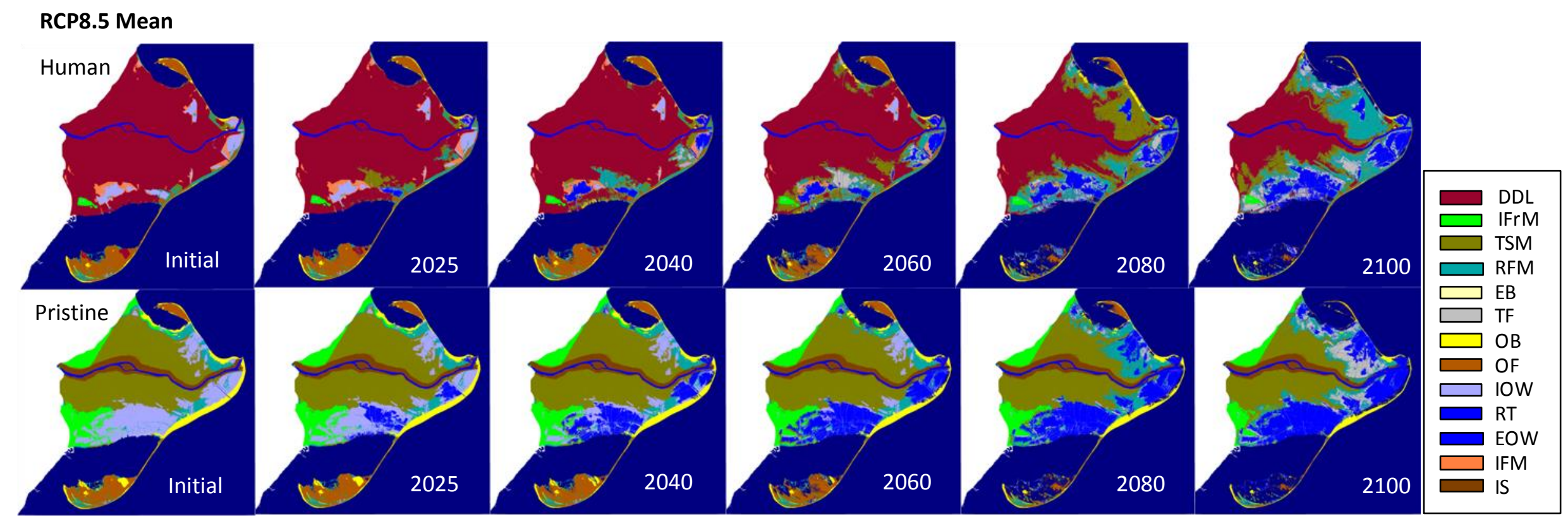

Fig. 5. Distributions of Ebro Delta habitats under the RCP 8.5 Mean scenario departing from human and pristine conditions until the end of the century. Habitat abbreviations as in Fig. 1. 


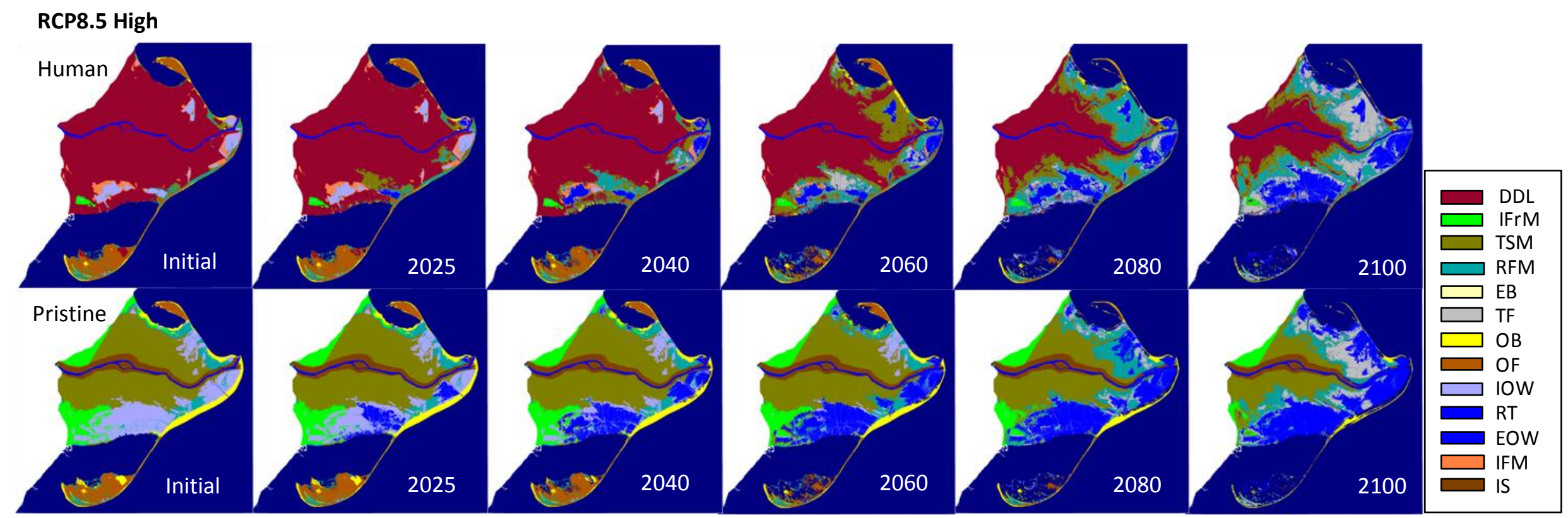

Fig. 6. Distributions of Ebro Delta habitats under the RCP 8.5 High scenario departing from human and pristine conditions until the end of the century. Habitat abbreviations as in Fig. 1. 


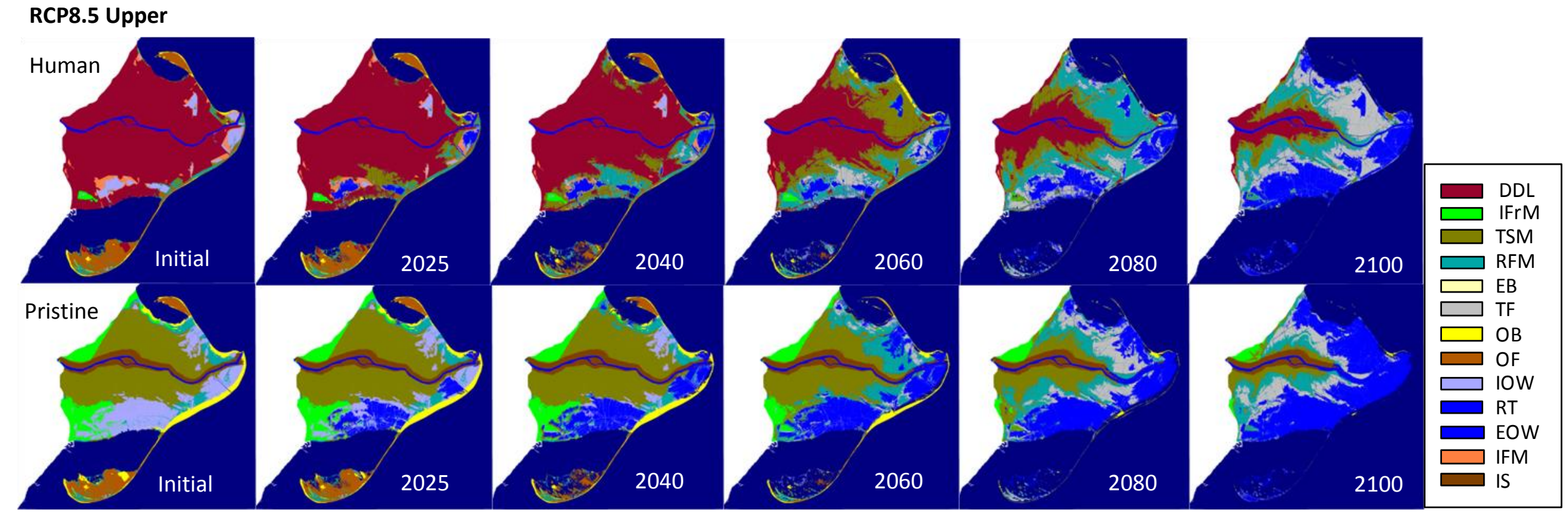

Fig. 7. Distributions of Ebro Delta habitats under the RCP 8.5 Upper scenario departing from human and pristine conditions until the end of the century. Habitat abbreviations as in Fig. 1. 